\title{
As concepções de aprendizagem de Paulo Freire aplicadas ao Ensino Superior em Direito
}

\author{
Las concepciones de aprendizaje de Paulo Freire aplicadas a la \\ Enseñanza Superior en Derecho \\ The learning conceptions of Paulo Freire applied to Law's Higher \\ Education
}

\author{
Marcele Pereira da Rosa Zucolotto ${ }^{1}$ \\ Marcos Antunes Kopstein ${ }^{2}$
}

\begin{abstract}
Resumo
Faz-se necessário um maior enfoque nos ideários pedagógicos propostos por Paulo Freire, o qual sempre pregou uma educação baseada na liberdade, na reciprocidade de conhecimentos entre professores e alunos, além do aprendizado através de trocas de saberes e não apenas na transmissão de conhecimento. Assim, não apenas o Ensino Inicial deve sofrer da influência das ideias do famoso pedagogo, mas também o Ensino Superior, com enfoque no Curso de Direito. O método de abordagem para construção do trabalho é o dedutivo, pautado por pesquisa bibliográfica por meio de livros e artigos científicos. Intuiu-se dessa maneira, dispor dos argumentos de Freire sobre a educação e como seus ensinamentos advindos dos estudos do pensador podem vir a modificar positivamente o ensino de Direito no Brasil. Como resultados da pesquisa, verificaram-se as dificuldades enfrentadas pelos estudantes perante um ensino engessado e que precisa urgentemente se renovar para se tornar mais integrador e libertador, conforme já predispunha Paulo Freire.
\end{abstract}

Palavras-Chave: Aprendizado; Educação; Paulo Freire.

\section{Resumen}

Se hace necesario un mayor enfoque en los idearios pedagógicos propuestos por Paulo Freire, el cual siempre predicó una educación basada en la libertad, en la reciprocidad de conocimientos entre profesores y alumnos, además del aprendizaje a través de intercambios de saberes y no sólo en la transmisión de conocimiento. Así, no sólo la Enseñanza Inicial debe sufrir de la influencia de las ideas del famoso pedagogo, sino también la Enseñanza Superior, con enfoque en el Curso de Derecho. El método de abordaje para la construcción del trabajo es el deductivo, pautado por investigación bibliográfica por medio de libros y artículos científicos. Se intuye de esta manera, disponer de los argumentos de Freire sobre la educación y cómo sus enseñanzas derivadas de los estudios del pensador pueden venir a modificar positivamente la enseñanza de Derecho en Brasil. Como resultado de la investigación, se verificaron las dificultades enfrentadas por los estudiantes ante una enseñanza enyesada y que necesita urgentemente renovar para volverse más integrador y liberador, como ya predispone Paulo Freire.

Palabras claves: Aprendizaje; Educación; Paulo Freire.

\footnotetext{
${ }^{1}$ Doutora em Psicologia Social e Institucional pela Universidade Federal do Rio Grande do Sul- UFRGS, Porto Alegre, Rio Grande do Sul, Brasil. E-mail: marcelepr@ hotmail.com.

${ }^{2}$ Especialista em Direito do Trabalho e Mestrando em Ensino de Humanidades e Linguagens pela Universidade Franciscana-UFN, Santa Maria, Rio Grande do Sul, Brasil. Bolsista PROSUC/CAPES. E-mail: marcoskopstein@hotmail.com.
} 


\begin{abstract}
There is a need for a greater focus on pedagogical ideas proposed by Paulo Freire, who always preached an education based on freedom, reciprocity of knowledge between teachers and students, and learning through exchanges of knowledge and not only in the transmission of knowledge. Thus, not only the Initial Education should suffer from the influence of the ideas of the famous pedagogue, but also the Higher Education, focusing on the Course of Law. The method of approach for construction of the work is the deductive one, ruled by bibliographical research through books and scientific articles. It was intuited in this way, to dispose of Freire's arguments about education and how his teaching from the studies of the thinker can change positively the teaching of law in Brazil. As a result of the research, it was verified the difficulties faced by students in the front of a retrograde teaching, which urgently needs to be renewed in order to become more inclusive and liberating, as Paulo Freire predisposed.
\end{abstract}

Keywords: Education; Learning; Paulo Freire.

\title{
1. Introdução
}

Atualmente, o Ensino Superior brasileiro é pautado por um sistema educativo conteudista, que visa, sobretudo, preparar os alunos para o mercado de trabalho. Apesar disso, o que se vê desse sistema é que os estudantes saem com muita bagagem teórica e pouca experiência prática, não conseguindo perceber a realidade social que os cerca, pelo excesso de conteúdos e pouca disponibilidade reflexiva nas faculdades e universidades do país, assim não se desenvolvendo criticamente e tendo dificuldades de aliar o extenso ensino teórico construído nas instituições do Ensino Superior com a realidade do período após a faculdade.

Levando-se em consideração este contexto, busca-se refletir sobre o Ensino Superior em Direito a partir do viés do pensamento do educador brasileiro Paulo Freire. Paulo Freire é um notório pensador reconhecido mundialmente, porém pouco conhecido entre estudantes e professores que não das áreas de pedagogia ou de cursos voltados para a área de educação, muito pouco aproveitado nos estudos e reflexões sobre o ensino superior em Direito.

Optou-se por abordar os ensinamentos deste autor principalmente em função de seus extensos estudos e desenvolvimento de uma concepção de aprendizagem inovadora e com uma visão pautada no diálogo entre professores e estudantes, focando-se na ampliação do saber através da desfragmentação do ensino e do sectarismo, sobretudo, por meio da liberdade de aprendizagem. O pensador, com isto, coloca a possibilidade de quebrar certas correntes de uma educação que oprime e impossibilita uma horizontalidade de troca de saberes, podendo possibilitar uma readequação no Ensino Superior, focando-se, mormente no Curso de Direito.

Antevê-se que o ensino em Direito no país, apesar de ser um curso da área das ciências humanas, enfoca grandemente em extensos conhecimentos teóricos como legislações, doutrinas, decisões dos tribunais brasileiros e estrangeiros, impossibilitando que os alunos e professores, pela grande quantidade de conteúdo, desenvolvam debates e diálogos sobre as 
disciplinas e discussões decorrentes dos mais variados assuntos relacionados às ciências sociais e humanas.

Ademais, a prática jurídica no decorrer da graduação muitas vezes é escassa, o que impossibilita os Bacharéis a desenvolverem empiricamente o lecionado no decorrer do curso, acarretando em maiores dificuldades de integração no mercado de trabalho após a colação de grau.

Destarte, os estudantes de Direito, assim como em qualquer curso de graduação no Brasil, podem sofrer em um ambiente de ensino opressor, com uma infinidade de conteúdo nos quais os alunos não anteveem a real praticidade de aprendizagem.

Objetiva-se desenvolver neste trabalho um estudo embasado nas reflexões de Paulo Freire sobre a educação e seus ideais acerca da aprendizagem, como a dodiscência, a educação construída a partir da prática, a horizontalidade e a troca de saberes entre docentes e discentes, focadas na readequação do ensino de Direito para assim fomentar uma nova visão desse curso tão importante para a sociedade brasileira. O método de abordagem é o dedutivo, enfocando o estudo através de livros e artigos científicos, assim, pautado pela pesquisa bibliográfica.

\section{Paulo Freire e a Educação}

Os estudos, as reflexões e as metodologias propostas e desenvolvidas por Paulo Freire reinventaram o ensino brasileiro, fomentando, acima de tudo, uma educação embasada no empirismo, uma vez que este importante pensador brasileiro entendeu que educar inicia-se com a prática.

Assim, o pedagogo expôs a necessidade da existência de uma relação de aprendizagem recíproca entre professores e alunos estimulada pela constante troca de saberes em sala de aula, evitando, consequentemente, uma educação dita como opressora e sectária (FREIRE, 2002). Dessa maneira, ele exprime que "o educador, que aliena a ignorância, se mantém em posições fixas, invariáveis. Será sempre o que sabe, enquanto os educandos serão sempre os que não sabem. A rigidez destas posições nega a educação e o conhecimento como processos de busca" (FREIRE, 1994, p. 34).

Interpreta-se dos ensinamentos de Freire que o ensino rígido, hierarquizante e embasado não na troca de conhecimentos, mas exclusivamente na transmissão de informações, aliena profundamente o estudante, incapacitando-o para o completo desenvolvimento de uma aprendizagem satisfatória. 
Cumpre gizar ainda que o ideário de Paulo Freire se alicerçou na quebra de paradigmas predispostos na sociedade brasileira com enfoque nos prejuízos decorrentes do autoritarismo proposto nas escolas do país que oprimiu (e ainda oprime) os estudantes, ao impedir a formação de uma conscientização face aos problemas enfrentados pela sociedade brasileira.

Corrobora com o exposto a análise de Ghiraldelli Júnior (2001) sobre as concepções freireanas acerca da ruptura de paradigmas e fomento da conscientização que a escola deveria contribuir aos alunos, explanando que:

\begin{abstract}
Mantenho, aqui, uma abordagem do ideário freireano como ele se colocou nos anos sessenta. Tal concepção afirmava ter o homem vocação para "sujeito da história", e não para "objeto", mas no caso brasileiro esta vocação não se explicitava, pois o povo teria sido vítima do autoritarismo e do paternalismo correspondente à sociedade herdeira de uma tradição colonial e escravista. Fazia-se necessário segundo tal concepção - romper com isso, "libertar o homem do povo" de seu tradicional mutismo. A pedagogia deveria, então, forjar uma nova mentalidade, trabalhar para a "conscientização do homem" brasileiro frente aos problemas nacionais e engajá-lo na luta política (GHIRALDELLI JÚNIOR, 2001, p. 100-101).
\end{abstract}

Destarte, a pedagogia segundo Freire tem papel fundamental na readequação do ensino para impelir uma mudança de mentalidade do brasileiro, para assim colocá-lo na luta contra tudo aquilo que o oprime.

A prática pedagógica que Freire propõe abarcar o não conformismo com a educação dominadora, questionando, maiormente, todas as formas de opressão, de apassivamento, de domesticação e de anulação da criticidade dos educandos (FREIRE, 1994).

Evidencia-se que o pedagogo sempre pairou em ideários socialistas e levou em consideração princípios de outros pensadores acerca de reflexões sobre o ensino, citando-se, sobretudo, Vygotsky para complementar seus ensinamentos na formulação de um ensino crítico-construtivista (JÓFILI, 2002). Para complementar tal entendimento, Jófili (2002, p. 195) explica que:

A compreensão do papel da educação no desenvolvimento dos seres humanos, partilhada por Vygotsky e Freire, é baseada na preocupação de ambos com o desenvolvimento integral das pessoas, na filosofia marxista, no enfoque construtivista, na importância do contexto social e na firme crença na natureza dos seres humanos.

Dessa maneira, por intermédio de uma percepção pedagogicamente construtivista, antevê-se que, segundo Freire, os educadores devem conviver comunitariamente com seus educandos, comungando com a constante troca de conhecimentos, "portanto, não existe 
aquele que sabe tudo e ensina, e aquele que nada sabe e é ensinado; o que existe é o educadoreducando, que convive e aprende a vida e os problemas da comunidade do educandoeducador" (GHIRALDELLI JÚNIOR, 2001, p. 102).

Verifica-se claramente que o pensamento de Paulo Freire objetiva a ampliação do caráter emancipatório da educação, caracterizado especialmente pela liberdade e pela humanização, através de uma teoria de conhecimento cimentada pela cultura e pelas relações humanas (FREIRE, 1994).

Assim, "através da problematização, educador-educando e educandos educadores poderiam fixar o ponto de partida para a conscientização" (GHIRALDELLI JÚNIOR, 2001, p. 102), gerando uma prática pedagógica que acarretaria numa ruptura com a opressão perpetrada pelo retrógrado sistema de ensino nas escolas e universidades do Brasil. Embasando-se desse modo nos ensinamentos freireanos, Ghiraldelli Júnior (2001, p. 103) conclui que:

A educação como conscientização seria, assim, "práxis social" de "libertação de todos os homens da opressão". O ato de desvelamento só se efetivaria por completo quanto educador-educando e educandos-educadores, juntos, conseguissem se engajar em um processo de transformação social.

Feitas tais considerações acerca dos pensamentos de Freire e sua relação com a situação escolar brasileira, cabe frisar que esses preceitos podem e devem ser aplicados em qualquer área de ensino, não somente nos ensinos básico e médio. Nesta direção, considera-se que o ensino nas faculdades e instituições de ensino superior no país também necessita de uma reformulação e de uma perspectiva mais voltada ao empirismo e no estreitamento das relações entre docentes e discentes através da construção de aprendizagens entre ambos.

O pensamento sobre a construção da aprendizagem desenvolvido por Freire baseado, principalmente no marxismo, segue o ideário da horizontalidade de aprendizagem, da dodiscência e da constante utilização dos saberes teóricos e práticos interconectados. $\mathrm{O}$ pedagogo intuiu elaborar, desse modo, uma maior leitura do mundo, do mapeamento da realidade, inter-relacionando os saberes dos educadores e dos educandos.

Quanto ao conceito de dodiscência, uma mescla dos termos docente e discente, podese enquadrá-lo como uma caracterização de postura do educador como eterno aprendiz, ou seja, uma postura na qual ele esteja sempre disposto a aprender não somente com seus estudos e conhecimento, mas também com o de seus educandos, perpetuando assim a troca de saberes (FREIRE, 1994). 
Por consequência, a aprendizagem se torna mais permissiva a horizontalidade com relação ao docente e seus alunos, ampliando-se a gama de conhecimentos, de cultura e até mesmo de oralidade, visto que todos detêm um conhecimento prévio à escola que se choca com o novo saber que os educandos absorverão no ambiente acadêmico. Dessa forma, a horizontalidade de aprendizagem enseja uma promoção de uma ação educativa mais integrativa, de conscientização e também libertadora das amarras da rigidez e da hierarquização do conhecimento, desenvolvendo-se entre os educandos uma maior noção reflexiva e de senso crítico, inclusive perante a realidade social que os permeia (FREIRE, 2007).

As intensas críticas de Paulo Freire ao sistema de ensino opressor são expostas no seu magnum opus “A Pedagogia do Oprimido", onde o autor expõe que:

\begin{abstract}
Por isto mesmo é que uma das características desta educação dissertadora é a "sonoridade" da palavra e não sua força transformadora. Quatro vezes quatro dezesseis; Pará, capital Belém, que o educando fixa, memoriza, repete, sem perceber $\mathrm{o}$ que realmente significa quatro vezes quatro. $\mathrm{O}$ que verdadeiramente significa capital, na afirmação, Pará, capital Belém. Belém para o Pará e Pará para o Brasil (FREIRE, 1994, p. 33).
\end{abstract}

Desse entendimento, percebe-se a real necessidade de uma significação do que é ensinado, reequilibrando os estudos por meio de uma interdisciplinaridade curricular e da desfragmentação dos conteúdos, ademais, o sectarismo educacional é prejudicial para o fomento de um melhoramento do ensino brasileiro em todos os setores.

Uma das prerrogativas dispostas por Freire é a que se tange no empirismo, tendo em vista que "a reflexão crítica sobre a prática se torna uma exigência da relação Teoria/Prática sem a qual a teoria pode ir virando blábláblá e a prática, ativismo" (FREIRE, 2007, p. 12).

Ou seja, a teoria sem prática se torna um mero aborrecimento para o aluno que até poderia decorar o conteúdo, mas nunca desenvolveria um "ativismo", algum senso de construtivismo e visualizaria a importância do aprendizado na sua realidade estudantil, social e, posteriormente, laboral.

A crítica elaborada pelo pensador concentra-se, principalmente, no que ele denomina como ensino bancário:

É isto que nos leva, de um lado, à crítica e à recusa ao ensino "bancário", de outro, a compreender que, apesar dele, o educando a ele submetido não está fadado a fenecer; em que pese o ensino "bancário", que deforma a necessária criatividade do educando e do educador, o educando a ele sujeitado pode, não por causa do conteúdo cujo "conhecimento" lhe foi transferido, mas por causa do processo mesmo de aprender, dar, como se diz na linguagem popular, a volta por cima e 
superar o autoritarismo e o erro epistemológico do "bancarismo" (FREIRE, 2007, p. 13).

Sinala-se, todavia, que o julgamento de Freire acerca do ensino "bancário" é pautado pela questão da transferência e não na possibilidade da construção de um aprendizado do conhecimento instigado pelos educadores em geral. Sobre isso, o estudioso explana que:

Saber que ensinar não é transferir conhecimento, mas criar as possibilidades para a sua própria produção ou a sua construção. [...] É preciso insistir: este saber necessário ao professor - que ensinar não é transferir conhecimento - não apenas precisa de ser apreendido por ele e pelos educandos nas suas razões de ser ontológica, política, ética, epistemológica, pedagógica, mas também precisa de ser constantemente testemunhado, vivido. (FREIRE, 2007, p. 21).

Trazendo as críticas de Freire ao Ensino Superior, antevê-se que os mesmos erros cometidos no Ensino Básico são reprisados na graduação, uma vez que a ocorrência do ensino "bancário" de transmissão de conhecimento parece permear quase todo o período da graduação.

Por consequência, afirma-se que Freire já previa a real necessidade de uma readequação e enriquecimento da educação brasileira em geral para assim fomentar a criação de uma mentalidade mais crítica nos estudantes. Assim, faz-se oportuno dar maior ênfase na aplicabilidade das ideias freireanas ao Ensino Superior, mormente no Curso de Direito.

\section{Paulo Freire e o Ensino Superior em Direito}

Feitas as considerações acerca da compreensão de Paulo Freire a respeito do ensino e da importância da liberdade, da troca de saberes e da quebra de rigidez pedagógica, traça-se seus ideais e concepções para a esfera do Ensino Superior, focando-se no Curso de Direito. Dessa forma, visualiza-se a perspectiva de um melhoramento significativo na compreensão acerca da relevância da área jurídica para inclusive o crescimento da educação e da sociedade brasileira.

Deste modo, sob o enfoque das concepções pedagógicas freireanas, no Curso de Direito, consoante anterior exposição, vê-se que o excesso de teoria, pouca prática e uma extensa falta de comunicação e debates em sala de aula prejudicam a formação dos futuros Bacharéis em Direito.

Consoante o balizado, o desenvolvimento das práticas pedagógicas freireanas para os alunos do Curso de Direito acarretaria em uma educação mais construtivista e humanizada, o 
que é vital para o fomento de um maior senso de cidadania, de humanidade e de diálogo para um Bacharel apto a enfrentar os conflitos demandados pela sociedade. Segundo Ghiraldelli Júnior (2001, p.102), os pressupostos de Freire consistem na ideia de que:

[...] todo ato educativo é um ato político e que o educador "humanista revolucionário", "ombreado com os oprimidos", deveria colocar sua ação políticopedagógica a serviço da transformação da sociedade e da criação do "homem novo". Essa educação, ao contrário da "educação bancária", deveria problematizar as situações vividas pelos educandos, promovendo a passagem da "consciência ingênua" para a "consciência crítica".

O próprio pensador explica o significado e sentido da uma educação bancária, contra a qual seu pensamento se erige, exprimindo que:

\begin{abstract}
Em lugar de comunicar- se, o educador faz "comunicados" e depósitos que os educandos, meras incidências, recebem pacientemente, memorizam e repetem. Eis aí a concepção "bancária" da educação, em que a única margem de ação que se oferece aos educandos é a de receberem os depósitos, guardá-los e arquivá-los. Margem para serem colecionadores ou fichadores das coisas que arquivam. No fundo, porém, os grandes arquivados são os homens, nesta (na melhor das hipóteses) equivocada concepção "bancária" da educação. Arquivados, porque, fora da busca, fora da práxis, os homens não podem ser. Educador e educandos se arquivam na medida em que, nesta destorcida visão da educação, não há criatividade, não há transformação, não há saber. Só existe saber na invenção, na reinvenção, na busca inquieta, impaciente, permanente, que os homens fazem no mundo, com o mundo e com os outros. Busca esperançosa também (FREIRE, 1994, p. 33).
\end{abstract}

Sendo assim, percebe-se que todo o trabalho de Paulo Freire se opõe tangencialmente à concepção de "importar ideias", ao invés de "recriá-las" criticamente, sendo este último aspecto o que o autor sugere, profundamente, aos docentes e educadores em geral. A chave para compreender o que Freire propõe é a sua constante busca na formulação pedagógica para esboçar um construtivismo no decorrer da formação tanto dos educadores quanto dos educandos (FREIRE, 1977).

Ademais, uma nova era informacional e educativa surgiu no decorrer dos últimos anos, sendo que o método tecnicista de outrora já não mais é acolhido pelos jovens estudantes, que rejeitam formas rígidas e técnicas de "decorebas" de ensino perpetradas por educadores que não se adaptam a novas metodologias e práticas pedagógicas.

Freire, antes mesmo da redemocratização do país e do impulsionamento de novas práticas educativas, já estipulava isso ao afirmar que:

Preocupados com a questão da democratização da cultura, dentro do quadro geral da democratização fundamental, tínhamos necessariamente de dar atenção especial aos déficits quantitativos e qualitativos de nossa educação. Estes déficits, realmente 
alarmantes, constituem óbices ao desenvolvimento do País e à criação de uma mentalidade democrática. São termos contraditórios ao ímpeto de sua emancipação (FREIRE, 1967, p. 101).

Destarte, faz-se imperioso uma melhor assimilação dos ensinamentos de Freire na educação em geral, inclusive no Ensino Superior e em cursos chave para o desenvolvimento da sociedade brasileira, como o Curso em Direito. Consequentemente, o empirismo, a troca de conhecimento entre docentes e discentes, a busca por um fomento ao construtivismo estipulados por Freire alavancariam enormemente novos ideais tanto para estudantes como para operadores do Direito.

Haja vista, o Curso de Direito é pautado principalmente pelo estudo de regramentos, decisões do Poder Judiciário e análises interpretativas de legislações, ou seja, os alunos detêm pouquíssimo contato com a prática e com a realidade social que os cerca. A rigidez conteudista dentro do curso e o caráter por muitas vezes abstrato do que se é ensinado e estudado no Direito perfaz a necessidade de uma readequação de ensinança em certos aspectos e as ideias e percepções de Paulo Freire seriam assim muito interessantes para melhoramento desse quadro.

Desse modo, analisa-se a importância de um aprendizado multifocal e não só concentrado em teorias e doutrinas. As práticas, nas instituições de ensino no geral, necessitam de readequação e conforme Sacrístan (2000, p. 29):

As ideias pedagógicas mais aceitáveis e potencialmente renovadoras podem coexistir, e de fato coexistem, com uma prática escolar obsoleta. Tal incongruência e impotência para a transformação da realidade ocorrem, em boa parte, porque tal prática está muito ligada ao tipo de currículo contextualizado em subsistemas diversos e aos usos criados por seu desenvolvimento, ou que se expressam através dele, que permanecem muito estáveis. Por isso, a renovação do currículo, como plano estruturado por si só, não é suficiente para provocar mudanças substanciais na realidade. O discurso pedagógico se não totaliza toda essa trama de práticas diversas, não incide rigorosamente em sua análise e será incapaz de proporcionar verdadeiras alternativas de mudança nas aulas.

Desse entendimento, afirma-se que o enfoque construtivista deve ser valorizado pelos docentes, para assim alicerçar um ambiente educacional onde os alunos aprendam a desenvolver e contemplar seus conhecimentos, além de que a adaptabilidade aos diferentes pontos de vista poderá acarretar numa maior flexibilização do senso crítico dos estudantes (ZÓFILI, 2002).

Paulo Freire sempre frisou que a deficitária e autoritária educação no Brasil representava todas as mazelas político-sociais sofridas pelo povo em geral, pois a escola 
burocratizante e tecnicista sempre serviu aos propósitos de alienação da população (GHIRALDELLI JÚNIOR, 2001). Nesse ponto, todo o ideário freireano embasa-se na vital importância do professor para quebrar paradigmas:

\footnotetext{
Assim, o papel do docente se torna de suma importância, pois [...] a contribuição a ser trazida pelo educador brasileiro à sua sociedade em 'partejamento', [..] como de todos os especialistas voltados para a melhoria dos seus padrões haveria de ser a de uma educação crítica e criticizadora (FREIRE, 1967, p. 85-6).
}

Portanto, faz-se importante uma reanálise mais aprofundada dos ensinos e formulações das práticas pedagógicas propostas por Paulo Freire, uma vez que as novas caracterizações da sociedade brasileira demandam mudanças na forma de como se é realizado o ensino e em como se dá a relação entre educadores e educandos.

Destarte, vê-se no Curso de Direito um excesso de conteúdo teórico, não obedecendo à reciprocidade entre teoria e prática proposta por Paulo Freire, aliás, ele não é comumente estudado, ou ao menos citado, no decorrer do curso.

Ainda, pelo excesso de conteúdo e pela falta da prática pedagógica dos docentes do curso, visto que a maioria é formada por bacharéis, estes acabam por transmitir o saber por meio do uso de doutrinas, legislação ou jurisprudências, evitando o debate e discussão dos temas em sala de aula, assim a denominada dodiscência freireana não ocorre, prejudicando o estímulo ao senso crítico dos alunos e a caracterização do conteúdo apresentado em sala de aula na realidade vivida por eles.

Sendo assim, as reflexões propostas por Paulo Freire sobre a educação e suas concepções de aprendizagem mostram-se extremamente proveitosas ao ensino nos Cursos de Direito e mesmo ao ensino em outras graduações, no sentido de contribuir para construir e fomentar uma verdadeira conscientização, bem como o senso crítico e de cidadania nos estudantes.

\section{Conclusões}

A obra pedagógica de Paulo Freire, sempre imersa na luta contra a opressão desde o ensino, visando mudanças educacionais e autonomia para os professores desenvolverem conjuntamente com seus alunos uma educação libertária, deveria refletir positivamente em todos os setores de aprendizado na sociedade brasileira. Dessa maneira, o ideário freireano 
salientado em alguns aspectos neste artigo, podem devidamente ser reinventados e aplicados em qualquer área de ensino, sabidamente no Curso de Direito também.

O não conformismo de Freire com a educação que oprime foi um marco educacional que até hoje reverbera no ensino e na sociedade brasileira. A crítica ao sectarismo e desfragmentação em áreas de conhecimento e a busca por interdisciplinaridade de conteúdos nas instituições de ensino são vitais para uma mudança de mentalidade dos estudantes no país. Nesse sentido, as reflexões e mudanças propostas por Freire tornam-se fundamentais para, inclusive, ver-se um melhoramento, não só da educação brasileira, mas também da própria sociedade e política do país.

A teoria de conhecimento do pedagogo embasada em três aspectos fundamentais, quais sejam, liberdade, cultura e relações humanas, traz uma ampliação da leitura de mundo para professores e alunos, fomentando reciprocidades de conhecimento e uma contribuição significativa para a construção da aprendizagem.

Frisa-se quão importante se torna trazer os ensinamentos de Paulo Freire para o Ensino Superior, sobretudo ao Curso de Direito, uma vez que tais preceitos seriam de suma relevância para um advento de um curso mais humanizado e disposto ao diálogo construtivo e à troca de saberes.

Justifica-se assim, uma mudança de postura do próprio estudante que, dessa maneira, poderá desenvolver uma postura ética embasada numa consciência mais crítica, inspirando-se nisso para construir - tanto como futuro profissional como cidadão - uma sociedade melhor, corroborada pelo humanismo advindo dos ensinamentos de Paulo Freire e da ética que marca suas concepções pedagógicas.

\section{Referências}

FREIRE, Paulo. Ação Cultural para a Liberdade. (Cultural Action for Freedom) 2. ed. Rio de Janeiro: Paz e Terra, 1977.

. Educação como prática da liberdade. Ed. Civilização brasileira S.A, RJ, 1967.

. Pedagogia da Autonomia: saberes Necessários à Prática Educativa. 25ª Edição,

Ed. Rio de Janeiro: Paz e Terra, 2007.

. Pedagogia do Oprimido. 23a Reimpressão. ed. Rio de Janeiro, Paz e Terra, 1994.

GHIRALDELLI JÚNIOR, Paulo. Introdução à Educação Escolar Brasileira: História,

Política e Filosofia da Educação. 2001. Disponível

em:<http://www.miniweb.com.br/educadores/artigos/pdf/introdu-edu-bra.pdf >. Acesso em:

10 jun. 2018. 
JÓFILI, Zélia. Piaget, Vygotsky, Freire e a construção do conhecimento na escola. Revista Educativa, 2002. Disponível em:<https://www.maxwell.vrac.puc-rio.br/7560/7560.PDF>. Acesso em: 12 jun. 2018.

SACRÍSTAN, José Gimeno. O currículo: uma reflexão sobre a prática. Tradução: Ernani F.

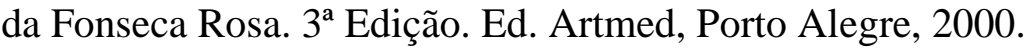

SCOCUGLIA, Afonso Celso. A História das Ideias de Paulo Freire e a Atual Crise de

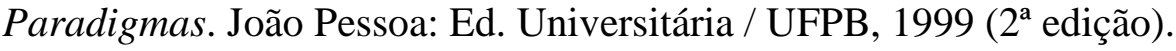

